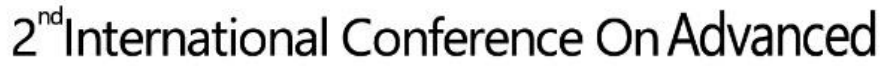 Research in HUMANITIES
}

\section{Social Interaction Attitudes Toward Gay and Lesbian Peers among Secondary School Students in Taiwan}

\author{
Te-Sheng Chang ${ }^{1}$, Chia-Sheng You ${ }^{2}$, Vuong Tran ${ }^{3}$ \\ ${ }^{1}$ National Dong Hwa University, Taiwan \\ ${ }^{2}$ Thompson Rivers University, Canada
}

\begin{abstract}
The purpose of this study was to investigate secondary school students' attitudes toward social interaction with gay and lesbian peers and to compare attitudinal differences between boy and girl students. The sample consisted of 813 (398 boys and 415 girl) students from eight schools in Hualien, Taiwan. The instruments used in this study were: "Attitudes Toward Social Interaction with Gay Peers" and "Attitudes Toward Social Interaction with Lesbian Peers". Each instrument consisted of three dimensions: "Friendship acceptance (Friendship)," "Identifying with gay or lesbian love (Love)," and "Sympathizing with gay or lesbian peers (Sympathy)." The results of this study indicate that the orders of participants' mean scores from low to high for the three dimensions of gay and lesbian peers are the same, namely, Love, Friendship, and Sympathy. There is a no significant interaction between participants' gender and the targets' sexual orientation on their attitudes toward social interaction with gay and lesbian peers. Both boy and girl students report more negative attitudes toward gay peers than lesbian peers in all the dimensions. Boy students report more negative attitudes towards gay peers and lesbian peers in all the dimensions than girl students. Implications of these findings for future research, programming, institutional support systems, and institutional policies for schools as they affect gay and lesbian students are discussed.
\end{abstract}

Keywords: gay and lesbian peers; secondary school students; sexual prejudice; social interaction attitudes; Taiwan 


\section{Carhconf}

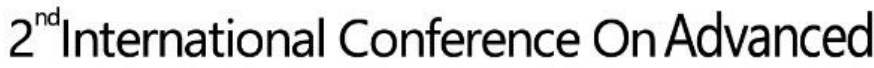 Research in HUMANITIES}

30 october - 01 November, 2019

MILAN, ITALY

\section{Introduction}

In Taiwan, the "Gender Equity Education Act" was put into effect on June 23, 2004. The Article 14 conforms that schools shouldn't discriminate against students because of their gender or sexual orientation and should affirmatively provide assistance to gay and lesbian students in order to improve their situations. However, some local news has reported that secondary school students are more prejudiced about gay and lesbian peers compared to students of other age groups in Taiwan. Research has shown that gender is one of the most consistent and reliable predictors of heterosexuals' attitudes toward gays and lesbians (Roper \& Halloran, 2007; Herek, 2002). Previous studies have emphasized that, in order to make campus atmosphere friendlier to gay and lesbian students, it is very important and crucial to understand students' attitudes toward gay and lesbian peers, particularly the association of students' gender and their attitudes toward gay and lesbian peers. What is the nature of secondary school students' attitudes toward social interaction with gay and lesbian peers? And what is the association of students' gender and social interaction with gay and lesbian peers? Without answering these questions, the prejudice against gay and lesbian peers cannot be solved and the goals of equity education for sexual minority cannot be achieved. Therefore, the purpose of this study was to identify secondary school students' attitudes toward gay and lesbian peers by examining a random sample from Taiwan. In addition, this study investigated students' gender difference in their attitudes toward social interaction with gay and lesbian peers.

\section{Research Method}

\subsection{Participants and Procedures}

The sample of 1000 secondary school students from 8 schools in Hualien, Taiwan were invited to participate in this research. A cross-section postal survey was distributed to the selected sample. Consent was obtained from the participating students before the study began. All study participants were heterosexual students who selected "heterosexual" for the "sexual orientation" item at the beginning of the questionnaire. In total, 813 valid questionnaires were used for analysis. The sample consisted of 215 (26.4\%) seventh graders, 242 (29.8\%) eighth graders, and 356 (43.8\%) ninth graders. Approximately, 49.0\% of the participants identified themselves as boy $(n=398)$ and $51.0 \%$ as $\operatorname{girl}(n=415)$.

\subsection{Measurements}

Participants' attitudes toward social interaction with gay and lesbian peers were measured by the two instruments: "Attitudes toward Social Interaction with Gay Peers (ASIG)" and "Attitudes toward Social Interaction with Lesbian Peers (ASIL)". Each of the instruments consisted of 10 social interaction situations followed by 10 bipolar adjectives (e.g., happy - sad; disapproving - approving; good - bad). Participants expressed their reaction toward each situation by indicating a point on a semantic differential scale (a Likerttype scale of 1 to 7) that best captured the magnitude of their reactions. The 10 items were divided into three subscales: Friendship, Love, and Sympathy. These subscales represented the dimensions found to be important in the students' attitudes of social interaction with peers in the previous study (Horn, 2006). 


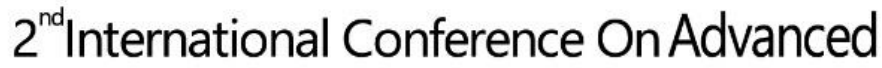 Research in HUMANITIES}

The Friendship dimension was designed to measure participants' acceptance of gay or lesbian friendship. This dimension was comprised of 4 attributes related to the idea "A gay student asks you if you are interested in working on the class project and presentation." The Love dimension was designed to measure participants' identifying with gay and lesbian love. Dimension Love was comprised of 3 attributes concerning that "You walk by male and male students sitting on a bench holding hands outside the student union." The Sympathy dimension was designed to measure participants' awareness of fairness and sympathy for gay and lesbian peers. This dimension was also comprised of 3 attributes with regard to the idea that "You learn that a gay resident down the hall is terminally ill."

In order to identify both overt and subtle attitudes toward gay and lesbian peers and control for social desirable responses, both of the instruments were in an identical form, with the exception that in each situation the ASIG scale refereed to gay peers, and the ASIL scale refereed tolesbian peers. Factor loadings for the ASIG, and ASIL designed to measure each factor were $.58-.86$ and $.61-.86$, respectively. The three factors accounted for $78.84 \%$ and $74.70 \%$ of the total variance for the ASIG and ASIL scales. The coefficients of internal consistency reliability were $.84-.91$ and $.80-.87$ for the ASIG and ASIL.

\subsection{Data Analysis}

The data were analyzed by using a mixed-design analysis of variance (ANOVA) to understand the attitudes of boy and girl students toward the social interaction with gay and lesbian peers and to test for an interaction effect. The independent factor was the gender of the participants and the dependent factors were the participants' attitudes toward gays and lesbian peers. The interaction effect was validated if the two-way ANOVA results were significant. Because the social interaction in this study included three dimensions, the assumed error rate was set to $0.017(0.05 / 3)$ for each of the interaction tests. A simple main effect comparison was further conducted for dimensions that were significant. The discussions were based on the simple main effect results for significant interactions and on the main effect for interactions that did not reach significance levels.

\section{Results}

\subsection{Attitudes toward Social Interaction with Gay and Lesbian Peers}

The attitudes score of boy and girl students toward gay and lesbian peers are shown in Table 1. The ranges of the means of social relationships dimensions for all participants are 3.36 to 5.91. The orders of participants' mean scores from high to low, across the three social interaction dimensions, are the same for gay and lesbian peers. That is, students give the sympathy dimension the highest score, followed by the friendship, and love dimensions the last. Girl students give higher scores than boy students across these three dimensions of social interaction with gay and lesbian peers, respectively. The only two mean scores lower than 4.0 occur in boy's attitudes toward their identifying with gay love (3.36) and lesbian love (3.96). 


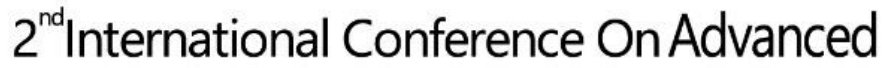 Research in HUMANITIES}

30 october - 01 November, 2019

MILAN, ITALY

Table 1

The Means and Standard Deviations of Social Interaction as a Function of Student Gender and Peer's Sexual Orientation

\begin{tabular}{lcccc}
\hline Type of peers & \multicolumn{2}{c}{ Gay } & \multicolumn{2}{c}{ Lesbian } \\
\hline Dimensions & $M$ & $S$ & & $S$ \\
\hline Friendship & & & & \\
boy $(n=398)$ & $4.05^{\mathrm{a}}$ & 1.33 & 4.29 & 1.73 \\
$\quad$ girl $(n=415)$ & 4.89 & 1.08 & 5.06 & 1.43 \\
$\quad$ Total $(N=813)$ & 4.48 & 1.28 & 4.69 & 1.63 \\
\hline Love & & & & \\
$\quad$ boy & 3.36 & 1.80 & 3.96 & 1.75 \\
$\quad$ girl & 4.45 & 1.78 & 4.89 & 1.67 \\
$\quad$ Total & 3.92 & 1.87 & 4.43 & 1.77 \\
\hline Sympathy & & & & \\
$\quad$ Boy & 5.04 & 1.67 & 5.25 & 1.53 \\
$\quad$ girl & 5.81 & 1.26 & 5.91 & 1.21 \\
$\quad$ Total & 5.43 & 1.52 & 5.59 & 1.42 \\
\hline
\end{tabular}

M: mean; S: standard deviation; a: on a 7-point scale

\subsection{Gender Difference in Social Interaction with Gay and Lesbian Peers}

\subsubsection{Acceptance of Gay and Lesbian Friendship}

The mixed-design analysis of variance was conducted on a between-subject factor (gender) and on a withinsubject factor (attitudes toward gays and lesbians) to determine whether the attitudes of boy and girl students varied toward gay and lesbian peers in the context of friendship. The interaction effect of the students' gender and the sexual orientation of the target peer is not significant (see Table 2). However, both the main effects of student gender and the sexual orientation of the target peer are significant. The students score significantly lower for friendships with gay peers compared to friendships with lesbian peers. The attitudes of boy students toward gay and lesbian peers are significantly lower than that of the girl students.

Table 2

Analysis of Interaction Effects toward Friendship by Student Gender and Peer's Sexual Orientation

\begin{tabular}{lllll}
\hline & \multicolumn{1}{c}{$S S$} & $d f$ & $M S$ & $F$ \\
\hline Gender & 262.18 & 1 & 262.18 & $79.69 * * *$ \\
Object(Sexual Orientation) & 17.37 & 1 & 17.37 & $25.54 * * *$ \\
Gender $\times$ Object & 3.67 & 1 & 3.67 & .54 \\
\hline Error (Gender) & 2666.33 & 811 & 3.29 & \\
Error (Object) & 549.64 & 811 & .68 & \\
\hline \multicolumn{5}{c}{$* * * 001$}
\end{tabular}




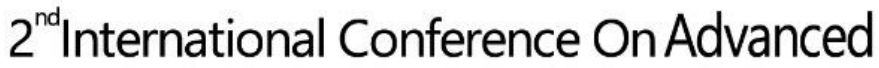 Research in HUMANITIES}

\subsubsection{Identifying with Gay and Lesbian Love}

In the dimension of love, the interaction effect of the students' gender and the sexual orientation of the target peer is not significant (see Table 3). The main effects of student gender and the sexual orientation of the target peer are significant. The students score significantly lower for their identifying with gay love compared to that with lesbian love. The attitudes of boy students toward gay and lesbian peers are significantly lower than those of the girl students. That is, boy students score significantly lower, for the love category questions, with gay peers compared with lesbian peers. The same results apply for the girl students as well.

Table 3

Analysis of Interaction Effects Toward Love by Student Gender and Peer's Sexual Orientation

\begin{tabular}{ccccc}
\hline Variables & $S S$ & $d f$ & $M S$ & $F$ \\
\hline Gender & 410.19 & 1 & 410.19 & $76.10^{* * *}$ \\
Object(Sexual Orientation) & 106.87 & 1 & 106.87 & $150.52^{* * *}$ \\
Gender × Object & 2.97 & 1 & 2.97 & $4.18^{*}$ \\
\hline Error (Gender) & 4372.39 & 811 & 5.39 & \\
Error (Object) & 575.92 & 811 & .71 & \\
\hline \multicolumn{5}{c}{$* * * p<.001$}
\end{tabular}

\subsubsection{Awareness of Fairness and Sympathy for Gay and Lesbian Peers.}

In the dimension of sympathy, the interaction effect of the students' gender and the sexual orientation of the target peer is not significant (see Table 4). The main effects of student gender and the sexual orientation of the target peer are significant. The students score significantly lower for sympathy with gay peers compared to sympathy with lesbian peers. The attitudes of boy students toward gay and lesbian peers are significantly lower than those of the girl students.

Table 4

Analysis of Interaction Effects toward Sympathy by Student Gender and Peer's Sexual Orientation

\begin{tabular}{ccccc}
\hline Variables & $S S$ & $d f$ & $M S$ & $F$ \\
\hline Gender & 209.93 & 1 & 209.93 & $55.98 * * *$ \\
Object (Sexual Orientation) & 9.82 & 1 & 9.82 & $29.76 * * *$ \\
Gender $\times$ Object & 1.16 & 1 & 1.16 & 3.51 \\
\hline Error (Gender) & 3037.94 & 811 & 3.75 & \\
Error (Object) & 269.00 & 811 & .33 &
\end{tabular}




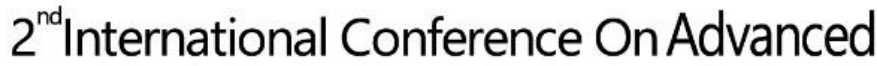 Research in HUMANITIES}

30 october - 01 November, 2019

MILAN, ITALY

\subsection{Discussion}

This study shows some interesting and noteworthy findings. First of all, both boy and girl students indicate that the orders of means from high to low for the three social interaction dimensions for gay peers and lesbian peers are the same, namely, Sympathy, Friendship, and Love. The results of this study suggest that secondary school students' attitudes toward gay and lesbian peers vary across the contexts of social interaction. In the context of sympathy, students report relatively positive attitude score toward both gay and lesbian peers. On the other hand, both girl and boy students still report low attitude scores toward the same-sex love. The implication of this study to schools is that gay and lesbian education with the context of sympathy cases may be more acceptable for secondary school students.

Second, there is no significant interaction between participants' gender and the sexual orientation of the target on their attitudes toward social interaction with gay and lesbian peers. Girl students indicate more positive attitude scores in all social interaction dimensions than boy counterparts. Both boy and girl report higher scores for lesbian peers compared to gay peers for all the dimension of social interaction. And the only two mean scores lower than 4.0 occur in boy's attitudes toward their identifying with gay love (3.36) and lesbian love (3.96). This finding is consistent with the results of previous studies (Roper \& Halloran, 2007) which outline that male students were more homophobic and held more negative views about homosexuals than female students. Herek (2002) suggested that the differences between male and female attitudes toward homosexuals might be due to homosexuals' gender, and the connotations and influence of a male-centered social system based on patriarchy.

\section{4- Conclusion}

What are the secondary school students' attitudes toward social interaction with gay and lesbian peers in Taiwan? The findings reported here suggest that both boy and girl students in Taiwan demonstrate the lowest scores in Love (the same-sex love for both gay men and lesbians). And female students show higher accepted score than their counterparts. These findings are in line with previous studies, although no previous study has raised questions pertaining to this aspect in detail. It is not surprising that students score lowest on the dimension of Love since the prejudice against lesbians and gay men has existed for years in Taiwanese society. Based on these findings, to reduce students' fear of accepting both lesbian and gay peers and to facilitate students' willingness to have contact with them should be the first priority actions for both the teachers and their institutes to take.

This study demonstrates the importance of examining the effect of students' gender and sexual orientation of the target on attitude toward gay and lesbian peers to more fully understand the scope and context of prejudicial attitudes. There are numerous implications for practice to consider from the results of this study, particularly in the areas of future research, programming, and strategies for supporting gay and lesbian students. The proposed steps for action should be a part of an institutional commitment to create welcoming, supportive climates for all our students, regardless of their gender and sexual orientation. 


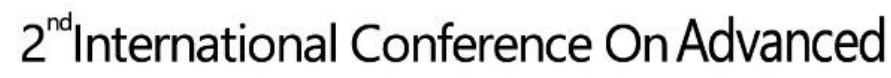 Research in HUMANITIES}

30 october - 01 November, 2019

MILAN, ITALY

\section{References}

[1] Herek, G. M. (2002). Gender gaps in public opinion about lesbians and gay men. Public Opinion Quarterly, 66 (1), 40-66.

[2] Horn, S. S. (2006). Heterosexual adolescents' and young adults' beliefs and attitudes about homosexuality and gay and lesbian peers. Cognitive Development, 21, 420-440.

[3] Roper, E. A., \& Halloran, E. (2007). Attitudes toward gay men and lesbians among heterosexual male and female student-athletes. Sex Roles, 57, 919-928. 